\title{
Inhibitors of Plasmepsin II - Potential Antimalarial Agents
}

\author{
Christoph Boss ${ }^{a *}$, Sylvia Richard-Bildstein ${ }^{\mathrm{a}}$, Rocco Furnari ${ }^{\mathrm{b}}$, Jean-Marc Bourgeois ${ }^{\mathrm{b}}$, Olivier \\ Corminboeufa ${ }^{a}$ Corinna Grisostomi ${ }^{a}$, Lionel Coppex ${ }^{\mathrm{a}}$, Luke Harris ${ }^{\mathrm{a}}$, Lars Prade ${ }^{\mathrm{a}}$, Solange Meyer ${ }^{\mathrm{a}}$, \\ Christoph Binkert ${ }^{\mathrm{a}}$, Walter Fischlia, Reto Brunc ${ }^{\mathrm{a}}$, and Thomas Weller ${ }^{\mathrm{a}}$
}

\begin{abstract}
Malaria is a very serious infectious disease affecting over two billion people worldwide. Currently available antimalarial drugs are losing effectiveness due to the emergence and the spread of resistant parasite strains. In order to regain control over the disease, new treatments are urgently needed. Drug discovery efforts in this direction are most likely to be successful if they target a novel mechanism of action. Such approaches will lead to antimalarial medicines that are functionally and structurally different from the existing drugs and therefore will have the potential to overcome existing resistances. Our own efforts are focused on the aspartic protease plasmepsin II (PMII) which is a promising new drug target for future antimalarial therapies. We have found structurally simple, moderately active, non-peptide inhibitors of plasmepsin II which offer ample opportunity for further optimization efforts.
\end{abstract}

Keywords: Aspartic proteases · Enzyme inhibitors · Malaria · Medicinal chemistry · Plasmepsin II (PMII)

\section{Introduction}

Malaria remains one of the world's most serious infectious diseases, besides tuberculosis and AIDS. Malaria is the most widespread parasitic disease in humans, with about $40 \%$ of the world's population $(\sim 2$ billion people) at risk of infection, mainly in tropical and subtropical areas. Of the four species of Plasmodium responsible for malaria in man, Plasmodium falciparum causes the highest mortality. Every year about 400 million clinical cases occur, resulting in more than 1 million deaths. Malaria kills one person every 12 seconds.

\footnotetext{
${ }^{*}$ Correspondence: Dr. C. Boss ${ }^{a}$

Tel.: +41614874561

Fax: + 41614874500

E-Mail: christoph.boss@actelion.com

aActelion Pharmaceuticals Ltd

Drug Discovery Chemistry \& Biochemistry

Gewerbestrasse 16

$\mathrm{CH}-4123$ Allschwil/BL

'Ecole d'ingénieurs et d'architectes de Fribourg

Département de chimie

Bd de Pérolles 80

$\mathrm{CH}-1705$ Fribourg

'Swiss Tropical Institute,

Socinstrasse 57

$\mathrm{CH}-4002$ Basel
}

About $90 \%$ of these cases can be allocated to Sub-Saharan Africa. The remaining cases are mostly confined to South and Southeast Asia and parts of South America. In these regions, malaria, besides torturing the infected individuals, also severely affects the functionality of societies and has a strong negative impact on the economic situation and certainly contributes to economic underdevelopment [1].

During recent years, several factors had a negative impact on the malaria problem:

1) Increased mobility of the population, climate changes, and novel agricultural practices have allowed the disease to spread into formerly unaffected regions.

2) Disease control in affected areas has been made difficult by political conflicts.

3) The appearance of mosquito vectors resistant to pesticides, as well as parasite strains resistant to standard drugs, has drastically reduced the effectiveness of most antimalarial drugs, especially chloroquine. The reduced effectiveness of this drug has been a major setback in the efforts to control or eradicate malaria, since chloroquine is cheap and it is safe to use in pregnant women. Resistance to other antimalarial agents such as sulfadoxine-pyrimethamine, mefloquine, quinine or amodiaquine has also become a serious issue. Halofantrine, one of the few remaining therapeutic compounds against resistant strains of parasites, requires high doses and therefore often leads to severe side effects. Artemisinin and its derivatives, a second group of drugs used against resistant strains, are 'fast-acting' drugs and should be administered in combination with a 'long-acting' drug in order to reduce recrudescence and to prevent or slow the development of resistances.

These facts clearly indicate the urgent need for the discovery of new antimalarial medicines. Future drugs most importantly must be cheap, effective and safe to use especially in children and in pregnant women. In order to minimize problems with existing resistances it is advisable to focus drug discovery efforts towards compounds with new mechanisms of action. To avoid or reduce the chance of side effects it is favorable to target parasite-specific enzymes or parasite-specific pathways [2]. Different new targets are under investigation, e.g. the falcipains or the plasmepsins I (PMI), II (PMII), and IV (PMIV) [3].

During the blood stage of its life cycle [4], the P. falciparum parasite reproduces asexually and requires enormous amounts of nutrients to proliferate. Because of the limited capacity to synthesize amino acids de novo, the parasites cover their needs by catabolism of human hemoglobin present in red blood cells. Hemoglobin degradation occurs within the food vacuole of the parasite and is mediated by a series of parasite 
specific proteolytic enzymes, e.g. aspartic proteases called plasmepsins, cysteine proteases called falcipains, or the metalloprotease falcilysin (Fig. 1). As hemoglobin degradation is a parasite-specific catabolic pathway, essential for the survival of the Plasmodia, the enzymes involved in this process fulfill the requirements as promising drug targets against malaria. Plasmepsins appear to be well-suited antimalaria targets, since their activity is necessary for the survival of $P$. falciparum parasites. The parasites are unable to proliferate in human red blood cells in vitro in the presence of inhibitors of aspartic proteases [6]. The attractiveness of plasmepsins as antimalarial drug targets is enhanced by the fact that only eight members belonging to the aspartic protease family are known in man which considerably reduces the risk of side effects. This is in contrast to other families of proteases, e.g. cysteine- or metallo-proteases, where dozens to hundreds of family members were identified in the human genome. PMII is an endopeptidase working best at low $\mathrm{pH}$. It initiates the hemoglobin degradation in the food vacuole of $P$. falciparum by cleaving the $\beta$-chain of hemoglobin between Phe33 and Leu34. The catalytic unit within the active site of the enzyme is formed by two aspartic acid residues (Asp34 and Asp214) [7]. The active site consists of a lipophilic pocket which is covered by a flexible loop region called the 'flap'. In order to allow the substrate to access the active site, the 'flap' has to open. It provides flexibility for the enzyme to change its conformation.

The design of protease inhibitors generally relies on a mechanism-based pharmacophore as the central binding unit. Usually a secondary alcohol is the structural element of choice to inhibit aspartic proteases. This element mimics the tetrahedral transition state during peptide bond cleavage by aspartic proteases and has been successfully used to develop potent inhibitors based on statines or hydroxyethylamine-units [8]. However, most of these inhibitors are derived from peptides and are therefore often characterized by metabolic instability, poor pharmacokinetic properties and the inability to penetrate cells. Other structural elements that have also been successfully applied in aspartic protease inhibitors so far are either secondary amines in 4-arylpiperidine derived compounds [9] or tertiary amines in fully substituted 4-aminopiperidine based inhibitors [10c][10d]. Potent, non-peptide, low molecular weight inhibitors of the aspartic protease PMII have been identified, as demonstrated by reports in the literature [10]. No reports of pre-clinical or clinical investigations of such compounds have been detected so far.

\section{Features of New Antimalarial Drugs}

Finding new antimalarial drugs still remains a challenging and difficult task. The future ideal medicine must combine several features in order to be useful and helpful

Hemoglobin
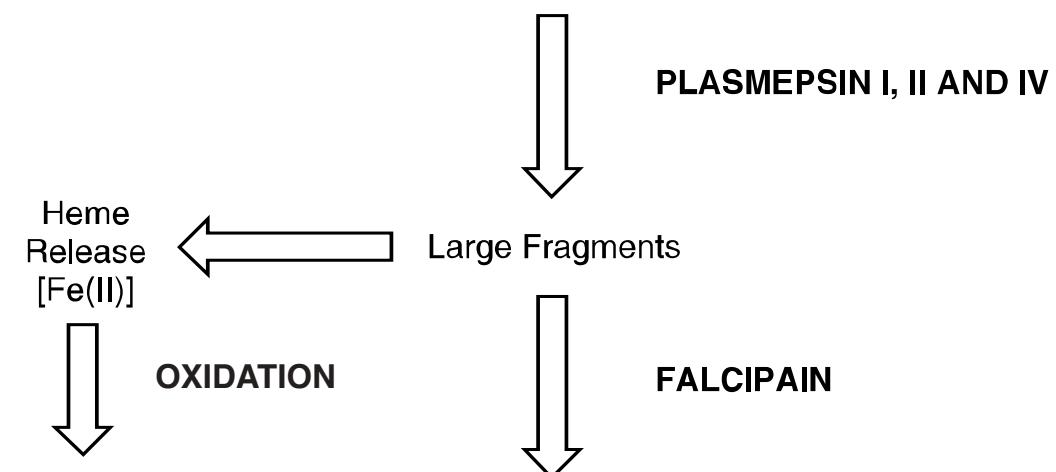

Hematin

[Fe(III)]

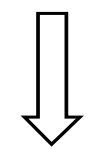

AGGREGATION

Hemozoin
Large Fragments

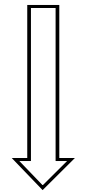

FALCIPAIN

Small Fragments

METALLOPROTEASES

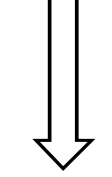

Small Peptides

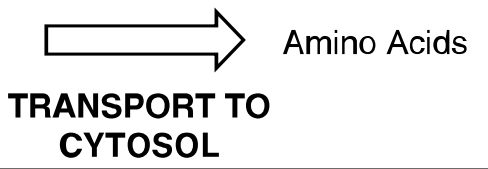
CYTOSOL

Fig. 1. Proposed hemoglobin degradation pathway within the food vacuole of $P$. falciparum [5]

where it is urgently needed:

- High efficacy against P. falciparum, including resistant strains

- No side effects which would limit its use, particularly in pregnant women or children

- Activity against the other species of plasmodium (e.g. ovale; vivax)

- Oral bioavailability

- Single dose treatment would be an asset

- Formulation must be stable in tropical climates

- Cost per treatment: max. 2 USD/1.65 Euro

\section{Plasmepsin II Inhibitors Based on Tertiary Amines}

In order to find a new drug which is able to fulfill the criteria listed above, it appears highly recommendable to look for new molecules from structurally different classes as compared to currently used antimalarial therapeutics. Therefore, and due to the general interest in aspartic proteases as drug targets, a high-throughput FRET assay was developed for PMII [11] and a commercial library of 50000 compounds was screened for inhibition of PMII activity. These efforts resulted in compounds which inhibited PMII at low $\mu \mathrm{M}$ concentrations (depicted in Fig. 2).

Structural analysis of the compounds depicted in Fig. 2 revealed the following features: i) an ethylene-diamine core unit, ii) a tertiary amine functionality, iii) two rather lipophilic substituents connected to the 2 nd end of the ethylenediamine unit, and iv) all inhibitors contain a 4-pentylbenzoyl substituent. A graphical summary is given in Fig. 3.

According to previous reports, it appears that an interaction of the inhibitor with the two aspartic acid residues of the active site should take place to provide efficient inhibition of the enzyme. The tertiary amine is the only group that can serve this function and therefore was considered to be mandatory. Consequently, the obvious questions were:

- What is tolerated as $\mathrm{R}^{3}$ and $\mathrm{R}^{4}$ ? Do the two groups have to be the same or can they be different?

- What is the ideal spacer?

- What is tolerated as A? (aryl? heteroaryl? cycloalkyl?; substitution pattern?)

- Is it possible to replace the 4-pentylbenzoyl-unit?

On the basis of lead compound 4 we decided to first tackle the questions with respect to the A- and B-groups. Compounds were prepared according to the general pathway depicted in Scheme 1 and summarized in Table 1. N,N-Dibutyl-ethylene-diamine (5) was alkylated in a reductive ami- 


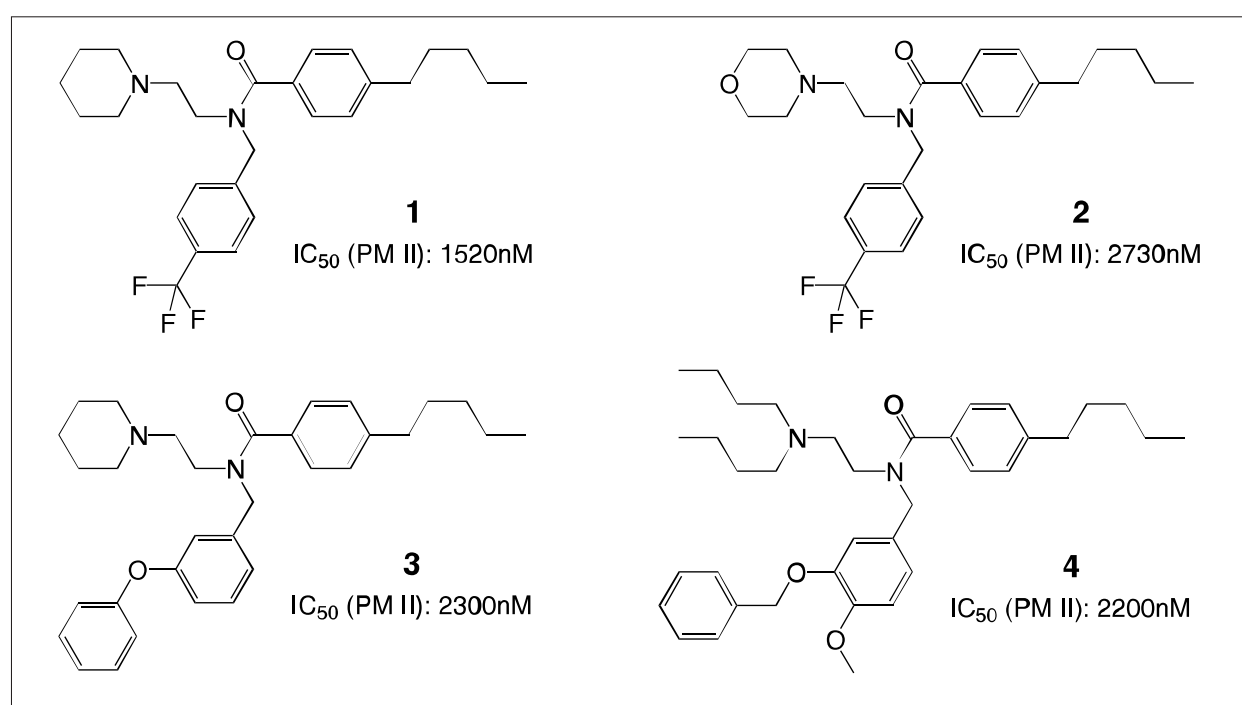

Fig. 2. Lead structures found by FRET high-throughput screening against plasmepsin II

nation procedure with an appropriate benzaldehyde derivative 6 to give the intermediate secondary amine 7 [12] which subsequently was acylated with substituted benzoylchlorides $\mathbf{8}$ to give a first set of final compounds $\mathbf{9 a - p}$ [7d].

Data collected in Table 1 show, that in position $\mathrm{R}^{1}$ several structurally different units might be tolerated, but a certain size of the substituent $\mathrm{R}^{1}$ seemed to be mandatory. The rather small $\mathrm{CF}_{3}$ group resulted in the lowest activity in all series. The most active compound $9 \mathbf{i}$ contained the benzyloxy group. This unit usually is prone to metabolic and chemical lability. We therefore decided to focus on compound $9 \mathbf{e}$, still showing reasonable inhibitory activity, incorporating $\mathrm{R}^{1}$ into a biaryl unit often seen in drug candidates or marketed drugs. Furthermore the biaryl unit offered a wide variety of chemical methods for the preparation of diverse derivatives or isosteres. With respect to group $\mathbf{B}$ it became obvious that the 4-pentyl-benzoyl unit was clearly superior to the other substituents, e.g. 4-butylbenzoyl, 4-propyl-benzoyl or 4-butoxybenzoyl, investigated in position B. Shortening the alkyl-chain or introducing heteroatoms led to substantial losses of inhibitory activity towards PMII.

Having set $\mathbf{A}-\mathbf{R}^{\mathbf{1}}$ as biphenyl and $\mathbf{B}-\mathbf{R}^{\mathbf{2}}$ as 4-pentyl-benzoyl respectively, we investigated the influence of the substituents $\mathrm{R}^{3}$ and $\mathrm{R}^{4}$. The small set of compounds prepared is shown in Table 2. Comparison of compounds 10a-d with 9e, the initial lead structure, indicates the superiority of lipophilic, sterically not crowded substituents in positions $\mathrm{R}^{3}$ and $\mathrm{R}^{4}$. The compounds of Table 2 were prepared in an analogous sequence as described in Scheme 1. We next focused our efforts on structural variations in the biaryl unit. Therefore, compounds $12 \mathbf{a}-\mathbf{r}$ were prepared by reacting precursor 11a with commercially avail- able boronic acids or precursor $\mathbf{1 1 b}$ with aryl- or heteroaryl bromides in a Suzuki reaction [13] (Scheme 2). The experimental set-up was optimized for parallel chemistry on a $0.1 \mathrm{mmol}$ scale. The Pd catalysts SKCC01-A and SK-CC02-A (commercially available from Fluka or Solvias AG) were chosen due to their superior stability, their broad scope/applicability and their excellent solubility in dioxane which allowed for easy addition to small vials via syringe/septum standard-techniques in parallel chemistry [14]. All final reaction products were purified by preparative reversed phase HPLC and analyzed by LC-MS and occasionally by NMR. Yields of final compounds after purification were in the range of $40-80 \% . \mathrm{IC}_{50}$ values against PMII and selected other aspartic proteases are given in Table 3. Compounds 12p-r, containing a heteroaryl ring in position $\mathbf{R}^{\mathbf{1}}$, exhibited PMII inhibitory activity in the same range as compound $9 \mathbf{e}$ with the unsubstituted phenyl ring in the respective position. Substitution with moderately polar, oxygen containing groups on the second aryl ring $\mathbf{R}^{\mathbf{1}}$, resulted in increased activity towards PMII (see compounds 12b,c,e,f). Car- boxylic acid functionalities either behaved neutral $(\mathbf{1 2 d}, \mathbf{g})$ or led to a reduction in activity (12h). Introduction of very lipophilic substituents such as $\mathrm{CF}_{3}$-groups $(\mathbf{1 2 l}, \mathbf{m})$ or the butyl group (120) also resulted in a moderate to strong loss of activity on PMII. With respect to inhibition of the human aspartic proteases cathepsin $\mathrm{D}$ (CathD), involved in intracellular digestion of proteins [15] and cathepsin E (CathE), involved in the generation of biologically active peptides [16], the compounds showed an acceptable selectivity towards PMII. The selectivity towards PMII is expected to increase with increasing potency for the inhibition of PMII.

In order to learn more about the influence of the conformationally restricted amide bond at the second nitrogen atom of the core unit, the 'diamine' compounds 13a-l (Table 4) were prepared. The synthesis started from compound 5 (Scheme 1), which was reacted either with 4-bromobenzaldehyde or with 4-formylphenylboronic acid under reductive amination conditions in order to obtain analogues of compound 7. Coupling with 4-pentyl-benzaldehyde according to a literature protocol [7d] provided the 'diamine' Suzuki precursors, which were converted to the final compounds 13a-l according to the procedures described in Scheme 2. Results summarized in Table 4 show that the 'diamine' compounds 13a-l were generally less active than their direct analogues from Table 3 , indicating the importance of the rotationally more restricted carboxamide group. With respect to substituents on the second aromatic portion the structure-activity pattern seemed to be quite similar as compared to the results of Table 3. The 'diamine'based compounds showed a decreased selectivity towards PMII over CathD and CathE, compared to the amine-amide analogues (e.g. compare 12b to 13a).

Finally, preliminary investigations of the spacer length between the two nitrogen atoms of the core unit were undertaken and the results are summarized in Table 5. Compounds $\mathbf{1 4 a}-\mathbf{j}$ were again prepared accord-

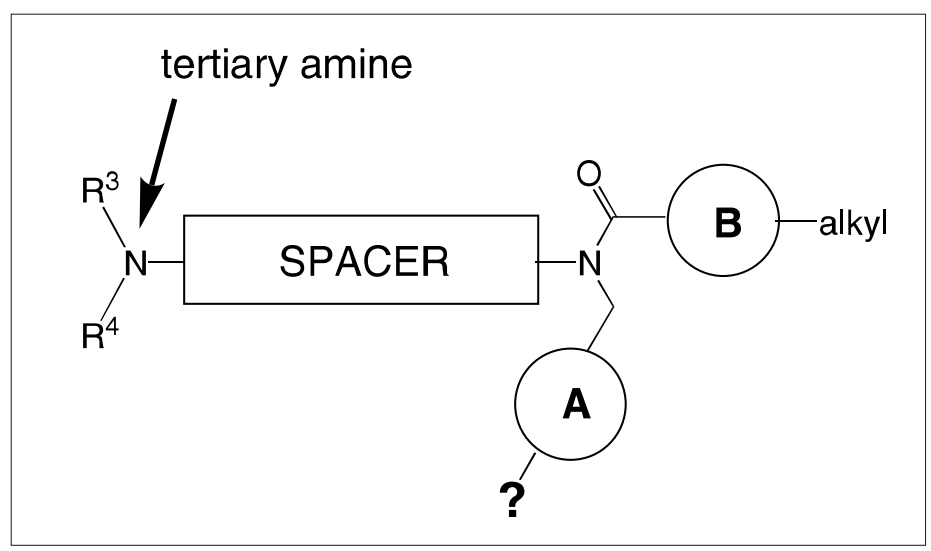

Fig. 3. General structure of plasmepsin II inhibitors 
Table 1. Biological data of the 1st set of plasmepsin II inhibitors

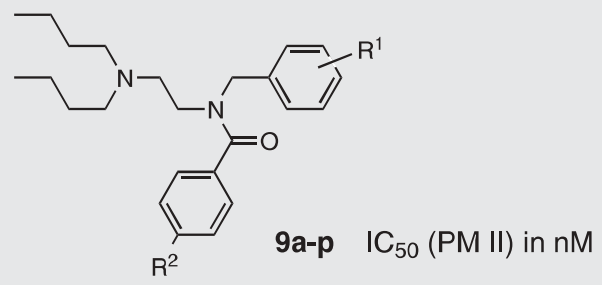

\begin{tabular}{|c|c|c|c|c|}
\hline & para & para & para & meta \\
\hline ' ${ }^{\prime} \mathrm{C}_{5} \mathrm{H}_{11}$ & $\begin{array}{c}\text { No: } 9 \mathbf{a} \\
I C_{50}: 596\end{array}$ & $\begin{array}{c}\text { No: } 9 e \\
\mid C_{50}: 252\end{array}$ & $\begin{array}{c}\text { No: } 9 \mathbf{9} \\
I C_{50}: 112\end{array}$ & $\begin{array}{c}\text { No: } 9 \mathrm{~m} \\
\mid \mathrm{IC}_{50}: 469\end{array}$ \\
\hline $\mathrm{C}_{4} \mathrm{H}_{9}$ & $\begin{array}{c}\text { No: } 9 \mathrm{~b} \\
I_{50}: 3900\end{array}$ & $\begin{array}{c}\text { No: } 9 f \\
I C_{50}: 1500\end{array}$ & $\begin{array}{c}\text { No: } \mathbf{9 j} \\
I C_{50}: 1300\end{array}$ & $\begin{array}{c}\text { No: } 9 \mathrm{n} \\
I_{50}: 2300\end{array}$ \\
\hline${ }^{\prime} \mathrm{C}_{3} \mathrm{H}_{7}$ & $\begin{array}{c}\text { No: } 9 \mathrm{c} \\
I \mathrm{C}_{50}: 39600\end{array}$ & $\begin{array}{c}\text { No: } \mathbf{9 g} \\
I C_{50}: 12900\end{array}$ & $\begin{array}{c}\text { No: } 9 k \\
I_{50}: 8900\end{array}$ & $\begin{array}{c}\text { No: } 90 \\
I_{50}: 15900\end{array}$ \\
\hline${ } \mathrm{OC}_{4} \mathrm{H}_{9}$ & $\begin{array}{c}\text { No: } 9 d \\
I C_{50}: 10300\end{array}$ & $\begin{array}{c}\text { No: } 9 \mathrm{~h} \\
I C_{50}: 4700\end{array}$ & $\begin{array}{c}\text { No: } 9 \mid \\
I_{50}: 3400\end{array}$ & $\begin{array}{c}\text { No: } 9 p \\
I C_{50}: 5900\end{array}$ \\
\hline
\end{tabular}

Table 2. Variations in $\mathrm{R}^{3}$ and $\mathrm{R}^{4}$<smiles>[R]N([Tl])CCN(Cc1ccc(-c2ccccc2)cc1)C(=O)c1ccc(CCCCC)cc1</smiles>

$\mathrm{IC}_{50}(\mathrm{PM}$ II) in $\mathrm{nM}$

$\mathrm{R}^{3}$

$\mathrm{R}^{4}$

$\mathrm{IC}_{50}$

Cpd.-No:

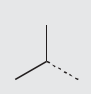

$10 a$

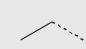

2317

$10 \mathrm{~b}$

$\mathrm{H}^{-\cdots}$

1161

$10 c$

$\mathrm{H}^{-}$

H

3329 ing to chemical steps outlined in Schemes 1 and 2 by using the template N,N-dibutylpropylene diamine. The amide substituent was kept constant as the 4-pentyl-benzoyl group. The picture obtained with respect to inhibitory potency towards PMII was unclear. The elongation of the linker to three carbons had a different impact on the requirements for $\mathbf{R}^{\mathbf{1}}$ as in the case of the $\mathrm{C}_{2}$ linker. The results called for further investigations of the spacer length $v s$. substitution patterns at the groups $\mathbf{A}-\mathbf{R}^{\mathbf{1}}$ and $\mathbf{B}-\mathbf{R}^{\mathbf{2}}$.

In order to get an idea about the antiparasitic activities of our PMII inhibitors,

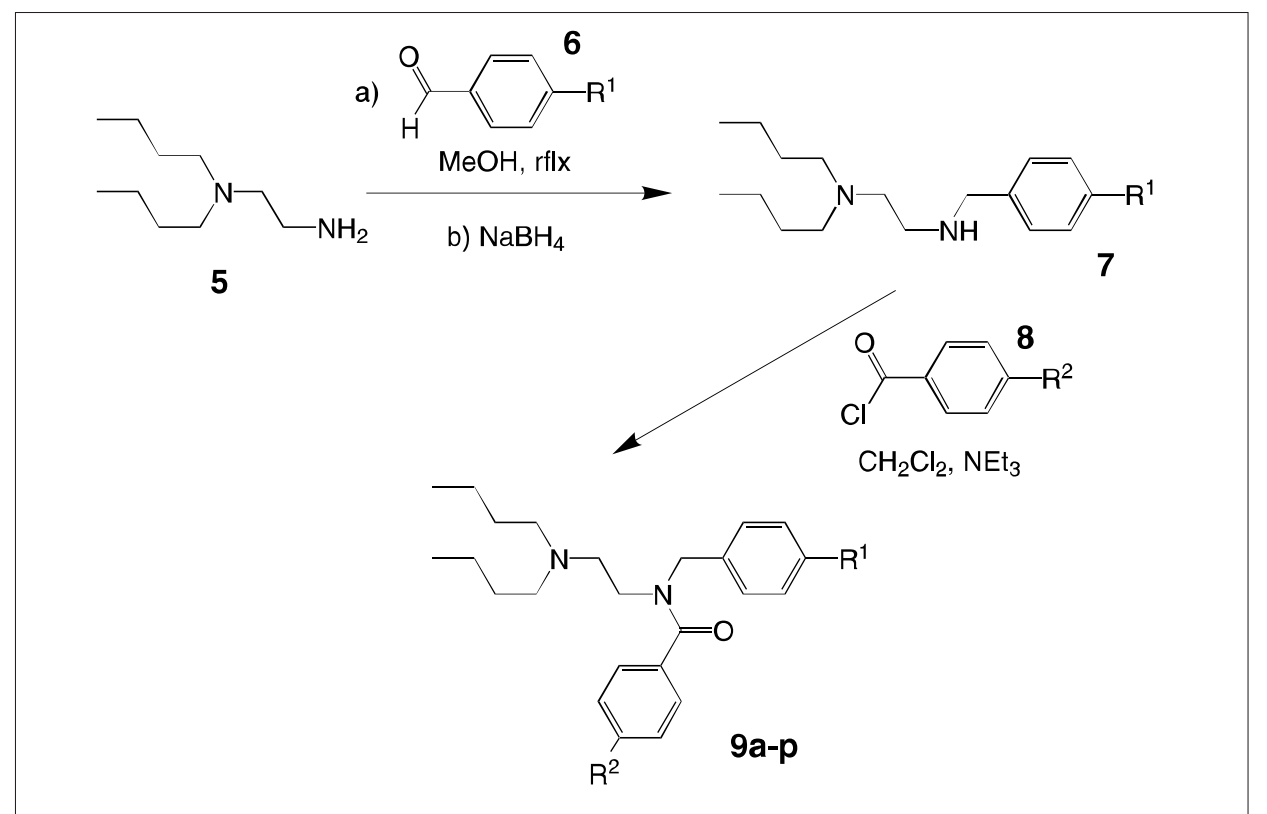

Scheme 1. Synthesis of the 1st set of plasmepsin II inhibitors the compounds were tested against $P$. falciparum $\mathrm{K} 1$ strain in human red blood cells (RBC) [17]. A selection of compounds is depicted in Table 6. Initial activities detected in the RBC assay were below $1 \mu \mathrm{M}$ which is promising and clearly shows the potential of the structural class of PMII inhibitors described in this account. The $\mathrm{IC}_{50}$ shifts from the isolated enzyme assay to the $\mathrm{RBC}$ assay are between 1 and 12 fold. In the diamine series (compounds 13, Table 4) the $\mathrm{IC}_{50}$ shifts are smaller as compared to the shifts observed in the amine-amide series (compounds 12, Table 3).

\section{Conclusions/Outlook}

We have presented the first results from a program aiming at the identification of small molecule, non-peptide inhibitors of the $P$. falciparum parasite aspartic protease PMII. A promising series of structurally simple lead compounds, accessible by straightforward chemistry, was identified. First optimization efforts have been performed, resulting in clear perspectives for further work: The length and the nature of the linker between the two nitrogen atoms relative to the substituents at the remaining positions has to be further investigated. The 


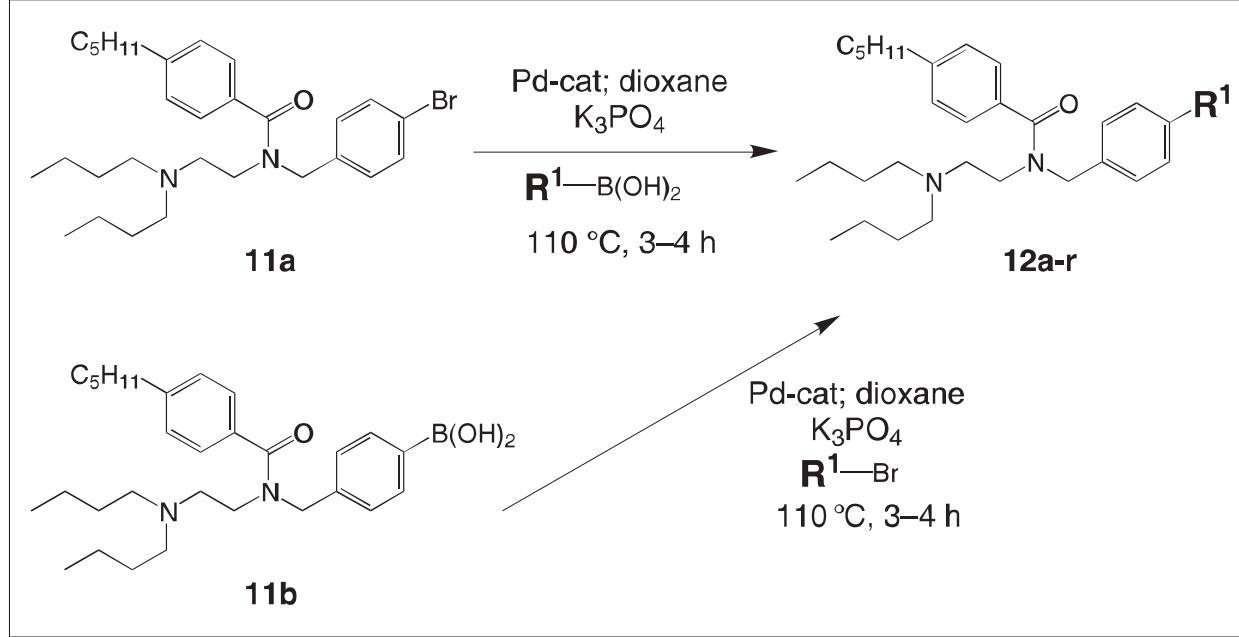

Scheme 2. Synthesis of the 2nd set of plasmepsin II inhibitors. Pd. cat: SK-CC01-A or SK-CC02-A from Solvias AG; a detailed description of the experimental procedure for the Suzuki reaction is given in [14].

\section{Table 3. Investigations of the biaryl unit}

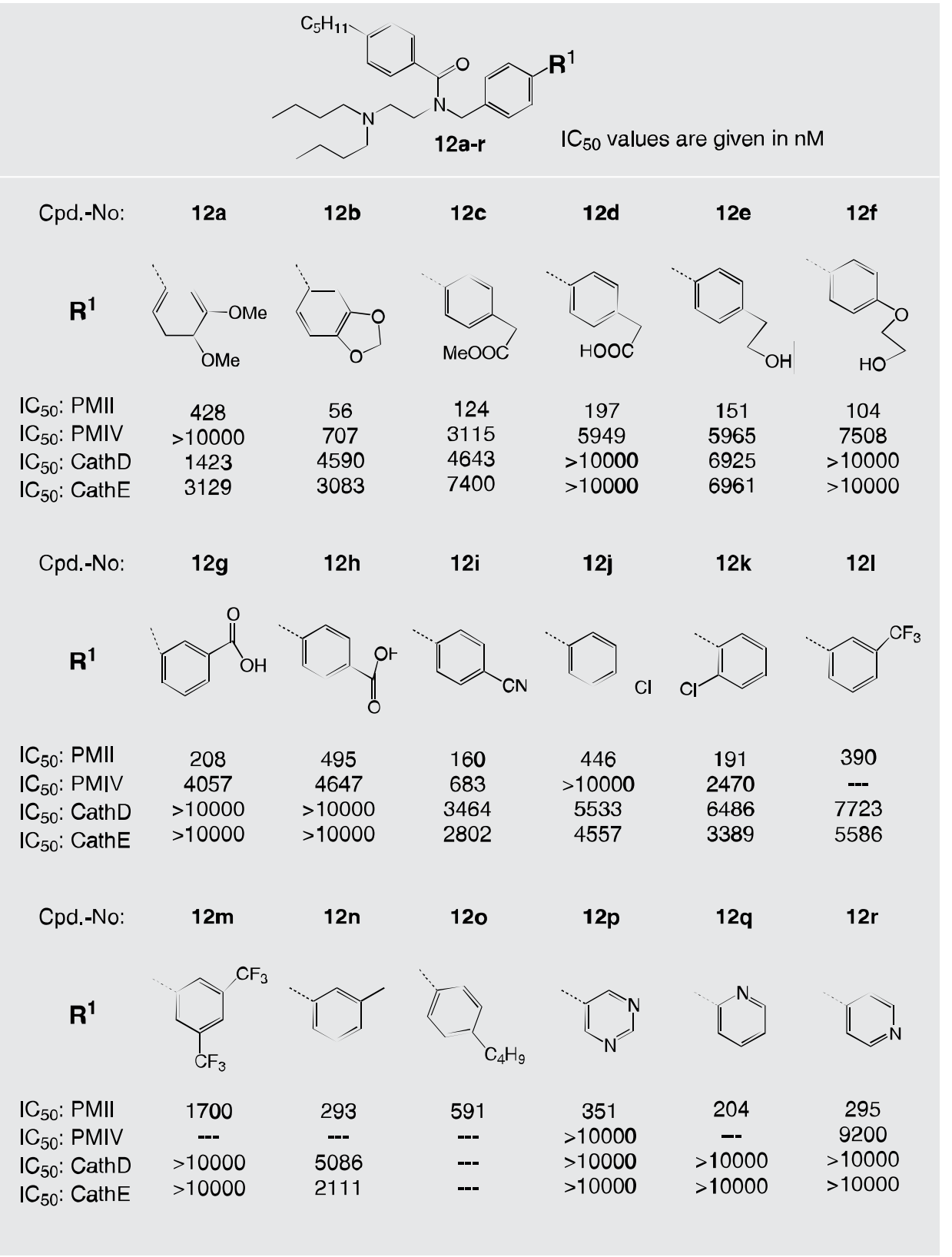

search for more drug-like replacements of the dibutyl-amino unit and for isosteric replacements of the biaryl unit is far from finished. Another feature of the present inhibitors asking for further optimization is the very lipophilic pentyl side chain which might be metabolically labile. Such compounds might exhibit a poor pharmacokinetic profile. We will further characterize the PMII inhibitors in secondary assays in whole cells in order to judge their potential for side effects. In addition we will try to solve the X-ray structure of PMII with an inhibitor described above in order to perform further work on a rational basis of molecular design.

\section{Acknowledgements}

The authors would like to thank Gabi Vorburger, Pascal Rebmann, Christine Berthion, Anne Bodlenner, Annabelle Gillig, Heiner Bammerlin, Walter Schmutz and Loic Dayon for expert technical assistance used for the synthesis, purification and characterization of compounds, Dr. Daniel Bur for helpful and stimulating discussions, and Prof. Henri Ramuz for his motivating constant support.

Received: June 18, 2004

[1] a) J.A. Radding, Annu. Rep.Med. Chem. 1999, 34, 159; b) D.F. Wirth, Annu. Rep. Med.Chem. 1999, 34, 349; c) R.G. Ridley, Nature 2002, 415, 686; d) J. Wiesner, R. Ortmann, H. Jomaa, M. Schlitzer, Angew. Chem. 2003, 115, 5432 .

[2] a) A. Bell, Curr. Opin. Anti-infect. Invest. Drugs 2000, 2, 63; b) P.J. Rosenthal, L.H. Miller, in 'Antimalarial Chemotherapy', Ed. P.J. Rosenthal, Humana Press, New Jersey, 2001, p. 3.

[3] a) C. Berry, Curr. Opin. Drug Disc. Dev. 2000, 3, 624. b) D.M. Wyatt, C. Berry, FEBS Lett. 2002, 513, 159.

[4] D.S. Fullerton, in 'Textbook of Organic Medicinal and Pharmaceutical Chemistry', Eds. J.N. Delgado, W.A. Remers, Lippincott-Raven Publishers, Philadelphia - New York, 1998, p. 235.

[5] a) J. Ziegler, R. Linck, D.W. Wright, Curr. Med. Chem. 2001, 8, 171; b) D.E. Goldberg, A.F.G. Slater, A. Cerami, G.B. Henderson, Proc. Natl. Acad. Sci. USA 1990, 87, 2931.

[6] A. Nezami, I. Luque, T. Kimura, Y. Kiso, E. Freire, Biochemistry 2002, 41, 2273.

[7] A.M. Silva, A.Y. Lee, S.V. Gulnik, P. Majer, J. Collins, T.N. Bhat, P.J. Collins, R.E. Cachau, K.E. Luker, I.Y. Gluzman, S.E. Francis, A. Oksman, D.E. Goldberg, J.W. Erickson, Proc. Natl. Acad. Sci. USA 1996, 93, 10034.

[8] a) D.J. Maly, L. Huang, J.A. Ellman, ChemBioChem 2002, 3, 16; b) T. Mineo, M.A. Avery, Chemtracts Org. Chem. 2001, 14, 518.

[9] A. Binggeli, V. Breu, D. Bur, W. Fischli, R. Gueller, G. Hirth, H.-P. Märki, M. Müller, C. Oefner, H. Stadler, E. Vieira, M. Wil- 
Table 4. Variations of the biaryl unit in the 'diamine' series

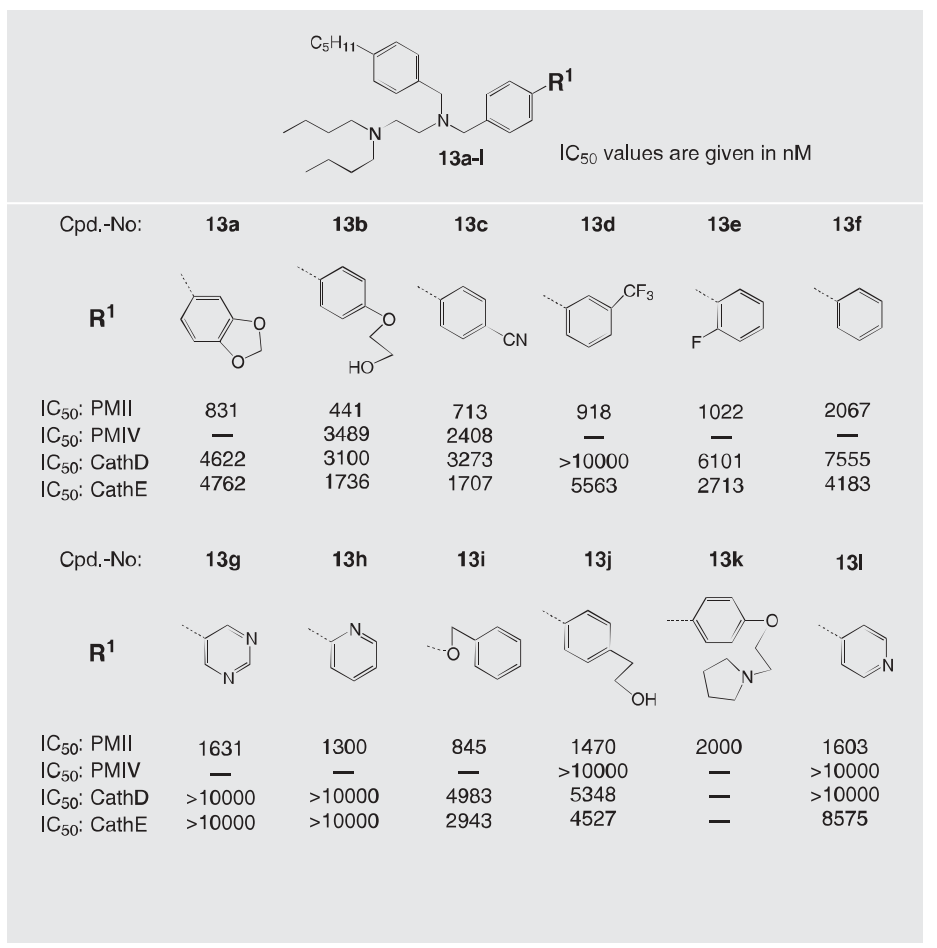

Table 6. Results of the compounds tested in P. falciparum infected red

blood cells (assay according to [17])
Cpd.-No: $\quad \mathrm{IC}_{50}$ (PMII in nM) $\quad \mathrm{IC}_{50}(\mathrm{RBC}$ in $\mathrm{nM}) \quad \mathrm{IC}_{50} \mathrm{RBC} / \mathrm{IC}_{50} \mathrm{PMII}$

\begin{tabular}{|c|c|c|c|}
\hline Cpd.-No: & $\mathrm{IC}_{50}(\mathrm{PM} \mathrm{II}$ in $\mathrm{nM})$ & $\mathrm{IC}_{50}(\mathrm{RBC}$ in $\mathrm{nM})$ & $\mathrm{IC}_{50} \mathrm{RBC} / \mathrm{IC}_{50} \mathrm{PMII}$ \\
\hline $9 e$ & 252 & 930 & 3.69 \\
\hline $12 b$ & 56 & 600 & 10.71 \\
\hline $12 c$ & 124 & 1280 & 10.32 \\
\hline 12d & 197 & 2290 & 11.62 \\
\hline $12 f$ & 104 & 762 & 7.33 \\
\hline $12 i$ & 160 & 780 & 4.88 \\
\hline $12 k$ & 191 & 718 & 3.76 \\
\hline $12 \mid$ & 390 & 990 & 2.54 \\
\hline $12 n$ & 293 & 650 & 2.22 \\
\hline $12 p$ & 351 & 810 & 2.19 \\
\hline $12 q$ & 204 & 1000 & 4.90 \\
\hline $13 a$ & 831 & 1228 & 1.48 \\
\hline $13 b$ & 441 & 522 & 1.18 \\
\hline $13 c$ & 713 & 514 & 0.72 \\
\hline $13 \mathrm{~g}$ & 1631 & 1668 & 1.02 \\
\hline $13 e$ & 1022 & 2719 & 2.66 \\
\hline
\end{tabular}

Table 5. Variation of the spacer length
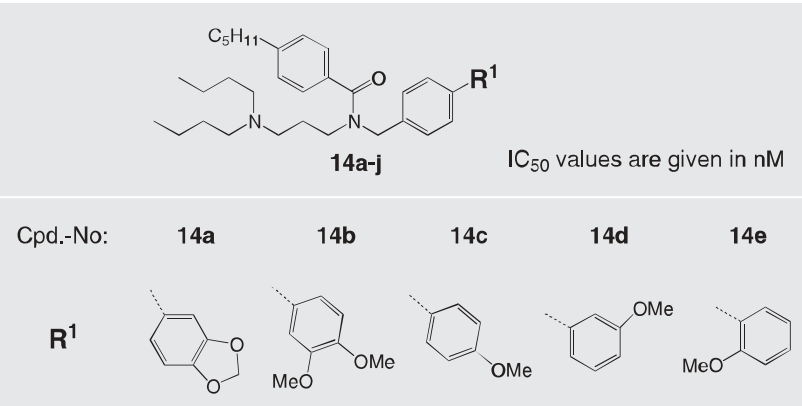

$\begin{array}{llllll}I^{\prime} \mathrm{S}_{50}: \text { PMII } & 195 & 468 & 246 & 580 & 1100\end{array}$

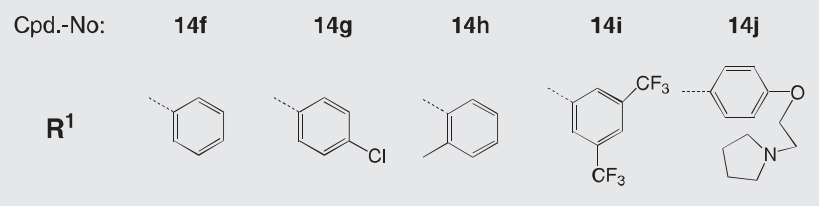

$\begin{array}{llllll}\text { IC }_{50}: \text { PMII } & 322 & 407 & 597 & 1190 & 221\end{array}$ helm, W. Wostl (F. Hoffmann-LaRoche Ltd) WO 09709311, 1997.

[10] a) D.A. Carcache, S.R. Hörtner, A. Bertogg, C. Binkert, D. Bur, H.-P. Märki, A. Dorn, F. Diederich, ChemBioChem 2002, 11, 1137; b) C. Boss, S. Richard-Bildstein, T. Weller, W. Fischli, S. Meyer, C. Binkert, Curr. Med. Chem. 2003, 10, 883; c) C. Boss, W. Fischli, S. Meyer, S. Richard-Bildstein, T. Weller (Actelion Pharmaceuticals Ltd) WO 00224649, 2002; d) C. Boss, W. Fischli, S. Meyer, S. Richard-Bildstein, T. Weller (Actelion Pharmaceuticals Ltd) WO 00238534, 2002.

[11] E.D. Matayoshi, G.T. Wang, G.A. Krafft, J. Erickson, Science 1990, 247, 954.

[12] A.F. Abdel-Magid, K.G. Carson, B.D. Harris, C.A. Maryanoff, R.D. Shah, J. Org. Chem. 1996, 61, 3849.

[13] N. Miyaura, A. Suzuki, Chem. Rev. 1995, 95, 2457.

[14] a) A. Schnyder, F. Naud, M. Thommen, H.U. Blaser, sp2 2003, 32; b) Solvias Application Note, 09/01, 2001; c) A. Schnyder, A.F. Indolese, M. Studer, H.-U. Blaser, Angew. Chem. Int. Ed. 2002, 41, 3668; d) A. Schnyder, T. Aemmer, A.F. Indolese, U. Pittelkow, M. Studer, Adv. Synth. Catal. 2002, 344.

[15] M.J. Hurley, L.B. Larsen, A.L. Kelly, P.L.H. McSweeney, Int. Dairy Journal 2000, 10, 673.

[16] P.J. Tatnell, W.E. Lees, J. Kay, FEBS Lett. 1997, 408, 62.

[17] R.G. Ridley, H. Matile, C. Jaquet, A. Dorn, W. Hofheinz, W. Leupin, R. Masciadri, F.P. Theil, W.F. Richter, M.A. Girometta, A. Guenzi, H. Urwyler, E. Gocke, J.M. Potthast, M. Csato, A. Thomas, W. Peters, Antimicrob. Agents Chemother. 1997, 41, 677. 